\title{
Foot Care Practice and Associated Factors among Patients with Lymphoedema in Boreda District, Gamo Zone, SNNPR, Ethiopia, 2020. Implications for Elimination of Podoconiosis and Lymphatic Filariasis
}

Chuchu Churko ( $\nabla$ churkochuchu2005@gmail.com )

Arba Minch University https://orcid.org/0000-0002-9132-9471

\section{Tsegaye Yohanes}

Arba Minch University

Alemayehu Bekele Kassahun

Arba Minch University

Nathan Desalign

Arba Minch University

Gisila Endashaw

Arba Minch University

Mekuria Asnakew Asfaw

Arba Minch University

\section{Research Article}

Keywords: podoconiosis, lymphatic filariasis, foot care practice, lymphedema, Ethiopia

Posted Date: June 11th, 2021

DOI: https://doi.org/10.21203/rs.3.rs-572573/v1

License: (c) (i) This work is licensed under a Creative Commons Attribution 4.0 International License. Read Full License

Version of Record: A version of this preprint was published at Journal of Foot and Ankle Research on August 10th, 2021. See the published version at https://doi.org/10.1186/s13047-021-00490-8. 


\section{Abstract}

Background: Lymphatic filariasis is ranked as the second leading cause of disability world-wide. The current global programme to eliminate lymphatic filariasis is based on the interruption of transmission and the alleviation of disability and suffering.

Objective: to assess foot care practice and associated factors among lymphoedema patients in Boreda district, Gamo zone Southern Ethiopia.

Methods: a community based cross sectional study was employed from December 2020 to June 2021 in Boreda district. Simple random sampling technique was used for selecting participants. Pretested structured interviewer administered questionnaire was prepared in English and translated to local language.

Findings: a total of 280 lymphedema patients were involved in this study. More than half $153(54.6 \%)$ had poor practice towards foot care practice with $95 \% \mathrm{Cl}(48.7 \%, 60.4 \%)$. Patients who fetched 50 litres or below and wore shoes at the age above 20 years were negatively associated with foot care practice, $(A O R=0.383,95 \% \mathrm{Cl}: 0.155,0.945)$ and $(A O R=0.261,95 \% \mathrm{Cl}: 0.107,0.63)$, respectively. Patients who owned only one pair and two pairs were negatively associated with foot care practice $(A O R=0.04,95 \% \mathrm{Cl}: 0.009$, 0.182 ) and (AOR $=0.27,95 \% \mathrm{Cl}: 0.087,0.85)$, respectively. On the other hand, attending LMMDP service and frequency of adenolymphangitis once and twice or more per month were positively associated with foot care practice $(\mathrm{AOR}=3.339,95 \% \mathrm{Cl}: 1.53,7.285)$ and $(\mathrm{AOR}=8.15,95 \% \mathrm{Cl}: 3.157,21.058)$ and (AOR=9.35, 95\% Cl: 3.118, 28.059), respectively.

Conclusion: this study indicated foot care practice among lymphedema patients in Boreda district was poor. Number of litre of water fetched per day, age at which shoes first worn, number of shoes owned, attending LMMDP and frequency of adenolymphangitis were significantly associated with foot care practice. Standard foot care practice should be emphasized to control progression of lymphedema.

\section{Introduction}

Podoconiosis and lymphatic filariasis (LF) are neglected tropical diseases (NTDs) that affect the world's poorest people and causes a significant economic, social and health burden to developing countries. ${ }^{1}$ Podoconiosis or 'endemic non-filarial elephantiasis' is a tropical disease caused by exposure of bare feet to irritant alkaline clay soils. This causes an asymmetrical swelling of the feet and lower limbs due to lymphedema. Podoconiosis has a curable pre-elephantiasic phase. However, once elephantiasis is established, podoconiosis persists and may cause lifelong disability. The disease is associated with living in low-income countries in the tropics in regions with high altitude and high seasonal rainfall. ${ }^{2}$ On the other hand, lymphatic filariasis or filarial elephantiasis, unlike podoconiosis is transmitted through the bite of an infected mosquito and mostly caused by an agent called Wuchereria 
bancrofti in Africa. It affected more than 36 million people globally and responsible for extremely complex physical, social and economic loss. ${ }^{3}$

Lymphatic filariasis also known as filarial elephantiasis has its own impact on health, social and economic well-being of affected population in the world. ${ }^{4}$ It is ranked as the second leading permanent disability. Physical and social lives as well as psychological wellbeing of patients with elephantiasis are significantly compromised due to the pain and discomfort, social stigmatization, restricted mobility, feelings of embarrassment and emotional distress that supplement these chronic disfiguring signs. ${ }^{5}$

Globally, it is predicted that, 120-129 million people are infected with LF and of these; around 40 million have overt disease, accounting for 5.9 million disability adjusted life years (DALYs), with a concomitant loss of productivity and social stigmatization. Therefore, World Health Organization (WHO) identified LF as a major public health problem and is targeted by for elimination by $2020 .^{6}$

Different literatures throughout the world revealed that practicing foot care has significantly reduced the frequency of acute attack secondary to lymphedema and progression of elephantiasis. Along with secondary infection and the resultant inflammation also seem to play major role in the skin changes seen in the limbs affected by lymphoedema, including the development of elephantiasis. ${ }^{7}$ Also, Olszewski reported that simple hygiene, supplemented with antibiotic treatment have profound effect in preventing these acute episodes. ${ }^{8}$ Shenoy et al. also demonstrated how well designed programmes of foot care can significantly decrease the frequency of ADL attacks and also promote to alleviate the disability. ${ }^{9}$

In such programmes, meticulous hygiene in treating the affected area needs to be incorporated with the creation of hope and understanding among the patients, their care providers and the community as a whole. ${ }^{10}$ As the minimum package of care, managing the lymphoedema seen in LF and podoconiosis patients to manage morbidity is very similar. It is practical that MMDP (morbidity management and disability prevention) should be integrated to help improve cost-effectiveness and extend the reach of the programme. $^{3}$

This is particularly important in Ethiopia where there is a high burden of both diseases, with 29 of the 70 LF-endemic districts considered to be co-endemic. ${ }^{[11,12]}$ Recently training on Lymphedema Morbidity Management and Disability Prevention for health care providers and NTD focals from 20 selected districts of SNNPR, Ethiopia was provided by Arba Minch University collaborative research and training centre for NTDs in collaboration with Ministry of Ethiopia. This will have impact on the way for elimination on podoconiosis by 2030 (i.e. reducing prevalence of podoconiosis below $1 \%$; ensure $100 \%$ access to lymphedema management in all endemic woredas and Ensure $70 \%$ regular shoe wearing and proper foot hygiene practice in all endemic woredas). ${ }^{13}$

Despite many efforts done by Ministry of health Ethiopia, burden of podoconiosis still exist in the country with average prevalence of $4 \%$ and the highest proportion of cases are found in Southern nation and nationality region accounting prevalence of podoconiosis $8.3 \%$. A more recent mapping data which is 
conducted in 2018 reported that a total of 16,929 leg lymphoedema was identified in the selected districts of SNNPR; out of this 1,084 lymphoedema cases reported in Boreda district, Gamo zone. ${ }^{14}$

The high number of leg lymphoedema cases in the current study area highlights the pressing need to deliver a basic package of care to those suffering from these disabling conditions, especially in areas with a high prevalence and/or high density of conditions where patients might be more readily found and the distribution of care easier. In this direction, it was essential to assess the current practices of foot care existing in the patients at community level, and no such information is available in Ethiopia. Hence, the present study was aimed to assess the foot care practices and associated factors among people living with lymphoedema in the rural communities of Gamo zone, SNNPR, Ethiopia, 2020.

\section{Methods And Materials \\ Study setting}

This study was conducted in Boreda district, Gamo zone, Southern Ethiopia. Boreda is one of the districts in Gamo zone with high number of elephantiasis case. It is bordered on the southeast by Mirab Abaya, on the southwest by Chencha, on the west by Kucha, and on the north by the Wolayita Zone. There is about 1,084 lymphoedema cases reported in the study area. ${ }^{14}$

\section{Study design and period}

- A community based cross-sectional study design was employed from January 1, 2021 to March 30, 2021

\section{Population}

\section{Source population}

- All individuals who have leg lymphoedema in Boreda district.

\section{Study population}

- Lymphedema cases in randomly selected kebeles (an aggregate of villages and the smallest administrative unit in Ethiopia).

\section{Eligibility criteria}

Inclusion criteria: individuals who had leg lymphoedema in the study area were included 
Exclusion criteria: individuals with leg lymphoedema other than podoconiosis and lymphatic filariasis, mental problems and severely ill during data collection period were excluded from the study.

\section{Sample size and sampling procedure}

Single population proportion formula was used to determine sample size and the following assumptions were used:

$$
n=\frac{Z^{2} * P(1-P)}{d^{2}}
$$

Where,

$\mathrm{n}=$ initial sample size

$P=50 \%$, to get the highest sample size on practice of foot care among patients

$d=$ margin of error $(0.05)$

$\mathrm{Za} / 2=$ significance level at $95 \%$ confidence interval $=1.96$

$$
\mathrm{n}=\frac{1.96^{2} * 0.5(1-0.5)}{0.05^{2}}=\underline{3.8416^{*} 0.25}=\quad \underline{0.9604}=384.16
$$

By considering non response rate $10 \%$, the sample size would be $384+38=422$.

Since total number of cases in the study area was 1084 which is less than 10,000 , we used finite population correction formula as follows:

$\mathrm{Nt}=\mathrm{n} 0 / 1+\mathrm{n} 0 / \mathrm{N}=422 / 1+422 / 1084=422 / 1+0.3893=422 / 1.3893=304=304$. Hence, the final estimated sample size was 304 .

From total of 29 kebeles in Boreda district, 10 kebeles were endemic for podoconiosis. Six endemic kebeles were randomly selected for data collection. Then number of lymphedema cases in each kebele was identified by health extension workers. The sample size was allocated proportionally to the size of cases in the selected districts. Finally, the study subjects were selected by using systematic sampling technique and selected cases were interviewed based on the pretested structured questionnaire (Figure 1).

\section{Variables}




\section{Dependent variable}

- Foot care practice (Good or Poor)

\section{Independent variables}

- Socio-demographic characteristics, economic factors, environmental factors, health related factors

\section{Plan for data collection}

Data was collected by using pretested structured interviewer administered questionnaire which was developed by reviewing different literatures. Eight data collectors and four supervisors having diploma and above holders with health background and have experience on any research undertakings were recruited for data collection. Each randomly selected patient was subjected to an interview by using a pretested structured questionnaire and asked how she/he dealt with lymphoedema particularly about the treatment, and regular foot care. Subsequently each patient was asked whether she/he practiced the identified foot care measures. We developed nine most commonly recommended foot care measures by reviewing available literatures. ${ }^{15} \mathrm{~A}$ patient was queried on each measure specifically and probed about different foot care practices in her/his daily life. The details of their socio-demographic, economic, personal hygiene and environmental factors, grade and duration of lymphoedema were recorded.

\section{Operational definition}

Lymphoedema: in this study lymphoedema was defined as lymphoedema of lower leg present for more than one year in a resident of an endemic area, for which other causes- e.g. onchocerciasis, leprosy, Milroy syndrome, heart and liver failures have been excluded. ${ }^{16}$

\section{Data quality control}

The data collection tool was reviewed by team members and then pretested on $5 \%$ of sample size outside actual study area. The tool was prepared in English then translated to local language by experienced translators and then back to English to check consistency. Data collectors and supervisors were trained on the tool and familiarized with it. Daily supervision and checking collected data for any missing values and inconsistency throughout data collection process was done by supervisors and investigators.

\section{Data processing and analysis}

After checking completeness of the collected data, entry of data was done by epi-info version 3.5.1 software and then exported to SPSS version 25 for cleaning, coding and analysis. For quantifying the 
level of foot care practice, we used nine most commonly recommended foot care measures and the correct answer was given 1 and 0 score for incorrect response. Patients who practice below the mean of practice question categorized as poor foot care practice and those patients who responded above the mean was considered as good foot care practice. Binary logistic regression analysis was employed to see association of independent variable with outcome variable. Factors which had p-value less than 0.25 during bivariate analysis were candidate for multivariate logistic analysis. Statistical significance was shown by $95 \%$ confidence interval and $p$-value $<=0.05$. Finally, the findings were presented in frequencies, graphs, tables and text.

\section{Result}

\section{Socio-demographic characteristic of the study subjects}

Of the total expected study subjects, complete data were collected from 280 individuals with response rate of $92.1 \%$. All $(100 \%)$ of the study subjects were living in rural area of Boreda district. One hundred twenty one (43.2\%), 60 (21.5\%) and $54(19.3 \%)$ of the participants are in the age group above 50 years, 31-40 years and $41-50$ years old, respectively. Female participants accounted 169 (60.4\%). Majority, 189 $(67.5 \%)$ were protestant religion followers and $78(27.9 \%)$ orthodox religion followers. Regarding ethnicity, most $263(93.9 \%)$ of them were Gamo ethnic group (Table 1).

\section{Home-environmental characteristics of lymphedema patients}

Eighty nine (31.8\%) of the study subjects said that one round walking distance to fetch safe drinking water was more than 30 minutes and more than three fourths fetch less than 50 litres per day. Majority, $264(94.3 \%)$ of the patients had functional pit latrine. Regarding weather and type of soil, $236(84.3 \%)$ and 228 (81.4\%) of the study participants live in lowland and red clay soil area, respectively (Table 2).

\section{Personal hygiene behaviour of lymphoedema patients in the study area}

Regarding personal hygiene, 167 (59.6\%) of the study subjects never walk barefooted whereas 33 (11.8\%) and 73 (26.1\%) become barefooted when farming and at home respectively. Most 196 (70\%) of study participants started wearing shoes at the age of 20 years or below. Fifty five $(19.6 \%)$ reported that they have only one pair of shoes whereas $186(66.4 \%)$ owned two pairs of shoes. On the conditions where patients take care for their legs, 137 (49\%) of patients wash legs with water and soap, 50 (20\%) wash legs with water only, $246(87.9 \%)$ and 215 (76.8\%) washed legs last night and daily last week, respectively (Table 3).

\section{Clinical history and characteristics of patients}

Majority 267 (95.4\%) of the respondents had no wounds on their legs and $13(4.6 \%)$ of them wounds present on their legs. Of those who had wounds on their legs, 9 (69.2\%) did not clean the wound. Two 
hundreds forty tree (86.8\%) of reported as they experienced acute attack (ALA). Out of these, forty three (17.7\%) did not knew the cause of acute attack, $48(19.7 \%)$ and $152(62.6 \%)$ said it occurs when they walk long distance and weather condition changes, respectively. More than half $134(55.1 \%)$ said that the acute attack occurs every year followed by monthly $68(28 \%)$ and more than once per week $41(16.9 \%)$ (Table 4).

In terms of duration of swelling, $60.7 \%$ said that it was 20 or fewer years, $35.4 \%$ said that it was 21 to 40 years duration and $3.9 \%$ said it was above 40 years. Fifty nine $(21.1 \%)$ reported that their family member was affected by leg swelling (Table 4).

\section{Accessibility to health care service}

Of the total respondents, $116(41.4 \%)$ did not attend LMMDP service because of different reason like didn't want 62(53.5\%), health facility far from home $7(6 \%)$ and no treatment centre available $47(40.5 \%)$. On the other hand, from those study subjects who attend LMMDP service, majority 154 (93.9\%) attended at health centre level and the rest $10(6.1 \%)$ got the service at hospital. Seventy $(42.7 \%)$ of the respondents did not train on self-management of the lymphedema and majority 263 (93.9\%) were not graduated from health extension packages (Table 5).

\section{Practice of study participants towards lymphedema morbidity management and disability prevention}

More than half 153 (54.6\%) of the study subjects had had poor practice of managing morbidity of lymphoedema with $95 \%$ confidence interval of (48.7\%, 60.4\%). Majority $257(91.8 \%)$ and $252(90 \%)$ had no habit of drying legs after washing and clean legs apart from washing, respectively. Most 201 (71.8\%) of the study subjects had habit of massaging their affected legs. One hundreds sixty six (59.3\%) and 206 (73.6\%) did not have the habit of elevating and exercising legs, respectively (Table 6) and (Fig. 2).

\section{Factors associated with foot care practice among people living with lymphoedema}

In bivariate analysis, wealth index, number of litres fetched per day, age at which shoes worn, number of shoes owned, duration of swelling occupation, age category, attended LMMDP treatment, experienced acute attack and frequency of acute attack became p-value less than 0.25 and therefore, were candidate for multivariate logistic regression model.

After adjusting for other variables, number of litre fetched per day per house, age at which shoes first worn, number of shoes owned, attended LMMDP treatment and frequency of acute attack were significantly associated with foot care practice. Patients who fetched 50 litres or below water were $38 \%$ less likely to have good foot care practice when compared to those patients who fetched more than 50 litres of water per day (AOR $=0.383,95 \% \mathrm{Cl}: 0.155,0.945)$. Study subjects who wore shoes at the age above 20 years were $26 \%$ less likely of having good foot care practice as compared to patients who wore 
shoes at age 20 years or below (AOR $=0.261,95 \% \mathrm{Cl}$ : $0.107,0.63)$. On the other hand, patients who owned only one pair and two pairs were $4 \%$ and $27 \%$ less likely to have good foot care practice in comparison with three or more pairs of shoes owned $(\mathrm{AOR}=0.04,95 \% \mathrm{Cl}: 0.009,0.182)$ and $(\mathrm{AOR}=0.27,95 \% \mathrm{Cl}: 0.087$, $0.85)$, respectively.

According to this study, participants who attended LMMDP service were 3 times more chance of good foot care practice than those who did not attend the service (AOR $=3.339,95 \% \mathrm{Cl}: 1.53,7.285)$. Likewise, frequent acute attack of adenolymphangitis was statistically significantly associated with good practice of foot care (AOR $=8.15,95 \% \mathrm{Cl}: 3.157,21.058)$ and (AOR $=9.35,95 \% \mathrm{Cl}: 3.118,28.059)$ (Table 7).

\section{Discussion}

This community based cross sectional study was conducted to assess foot care practice and associated factors among people living with lymphedema in Boreda district, Southern Ethiopia. The result of this study found that more than half $(54.6 \%)$ of study subjects had poor foot care practice. In contrast, a study done in Wolayta zone in 2016 showed that about $25.9 \%$ of the study subjects did not practiced stepwise treatment procedures provided by MFA health workers. ${ }^{17}$ This difference might be due to in our study area patients had less awareness and not well understood importance of practicing foot care and no much effort has been done to increase foot care practice.

In this study we found that patients who fetched 50 litres or below water per day were $38 \%$ less likely to have good practice of foot care when compared to those who fetched more than 50 litres of water per day. The possible reason might be the fact that accessibility to water is closely linked with personal hygiene practices. Ministry of health Ethiopia also recognized that high number of NTDs burden is linked with inadequate hygiene and sanitation

conditions, and it is now recognized globally that prevention and treatment of NTDs

must include water, hygiene and sanitation improvements (WASH) in addition to

mass drug administration (MDA). ${ }^{18}$

According to this study the study subjects who worn shoes first at the age of above 20 years old were $26 \%$ times less to practice foot care measures when compared to the counterpart. The lower the age of participants to begin wearing shoes the better practice of patients for their foot. This might indicate that people who started shoe wearing at early ages take care of themselves than others. To our knowledge, there is no previous literature conducted to discuss with this finding. This result is the first in its kind.

The present study revealed that number of shoes owned by the patients was significantly associated with foot care practice. Those study subjects who owned only one and two shoes were $4 \%$ and $27 \%$ less likely to practice foot care in comparison with patients with three or more shoes owned, respectively. This result might indicate the more number of shoes owned by the patients the better they take care of their foot. In 
addition to that those patients who owned three or more pairs of shoes might be in a good economic status and had access to services of lymphedema and afford consumables easily for their feet.

We found that frequency of acute attack was significantly strongly associated with good practice of foot care. Those patients who experienced one and more than one acute attack per month were 8 and 9 times more likely to have good foot care practice than patients who faced one ALA (acute adenolymphangitis) per year. The possible reason might be patients with more frequent acute attack of adenolymphangitis visit clinics for seeking treatment of the pain and thereby obtain information regarding foot care.

Although this study is the first in its kind to associate foot care practice with other variables, it has the following limitations: there might be recall bias regarding frequency of acute attack in a year and might not remember the exact age at which shoes first worn. This finding may not be generalizable to lymphoedema patients in Gamo zone because it is limited to Boreda district.

\section{Abbreviations}

ADL, Adenolymphangitis; ALA, Acute adenolymphangitis; AOR

Adjusted Odds Ratio; Cl, Confidence Interval; CMHS, College of Medicine and Health Sciences; DALYs, Disability Adjusted Life Years; LF, Lymphatic Filariasis; LMMDP, Lymphedema Morbidity Management and Disability Prevention; MDA, Mass Drug Administration; MFA, Mossy Foot Association; MMDP, Morbidity Management and Disability Prevention; NTDs, Neglected Tropical Diseases; PPS, Proportional to Size; SNNPR, Southern Nation Nationality People Region; SPSS, Statistical Package for Social Sciences; WASH, Water, Sanitation and Hygiene; WHO, World Health Organization

\section{Conclusion And Recommendation}

In conclusion, this study indicated foot care practice among people living with lymphoedema in Boreda district is poor. More than half of the study subjects had poor practice regarding foot care measures. In multivariable regression analysis variables like number of litre of water fetched per day, age at which shoes first worn, number of shoes owned, attending LMMDP treatment and frequency of acute attack were significantly associated with foot care practice. Therefore, standard foot care practice should be emphasized to control progression of lymphedema and improve care of patients towards practice measures. Shoe wearing habit at early age and other preventive strategies on podoconiosis and lymphatic filariasis should be practiced and implemented at Boreda district.

\section{Declarations}

\section{Ethical approval and consent to participate}

This study was ethically approved by Institute Research Board of Arba Minch University, CMHS, Ethiopia, (reference number, IRB/1031/21). The permission was obtained from Boreda district health office to conduct the study. The study subjects were informed about the objective of the study and took oral 
consent before data collection. The trained data collectors used the pretested structured questionnaires to ask the patients in their home. The respondent's confidentiality was maintained. All patients were educated on management of lymphedema after survey and they were linked to health facility which was near to them for morbidity management and disability prevention.

\section{Consent for publication}

Not applicable

\section{Availability of data and materials}

The datasets during and/or analysed during the current study are available from the corresponding author on reasonable request.

\section{Funding}

This study was funded by the Arba Minch University, College of Medicine and Health Sciences, collaborative research and training center.

\section{Conflict of interest}

The authors declare that they have no competing interests.

\section{Authors' contribution}

All authors made a significant contribution to the work reported, whether that is in the conception, study design, execution, acquisition of data, analysis and interpretation, or in all these areas; took part in drafting, revising or critically reviewing the article; gave final approval of the version to be published; have agreed on the journal to which the article has been submitted; and agree to be accountable for all aspects of the work.

\section{Acknowledgements}

We would like to express our deepest gratitude and appreciation to lord of wisdom, God. We are grateful to Arba Minch University Collaborative Research Training Center for Neglected Tropical Diseases for their full sponsorship of this research work. We are also grateful to all data collectors and supervisors, who tried their best and committed themselves to data collection.

\section{References}

1. World Health Organisation. Integrating neglected tropical diseases into global health and development: fourth WHO report on neglected tropical diseases. Geneva: World Health Organisation; 2017.

2. Korevaar ea. Podoconiosis, a neglected tropical disease. 201 2;7 0(5). 
3. WHO. Lymphatic Filariasis: an aide-memoire for national programme managers. 2013.

4. WHO. Bridging the Gap, The World Health Report, World Health Organization. Geneva, Switzerland. 1995.

5. Ramaiah KDVKK, Ramu K, Pani SP, Das PK. Functional impairment caused by lymphatic filariasis in rural area of south India. Trop Med Int Health. 1997;2:832-8.

6. A. F. The global burden of neglected tropical diseases.. Public Health. 2012;126(3):233-6.

7. Olszewski WL, Jamal S, Manokaran G, Lukomska B, Kubika U, Swoboda E, Dworczynski A. Skin changes in filarial Lymphedema. Progress of Lymphology. 1992;13:193-5.

8. Olszewski WL. Episodic dermatolymphangitis (DLA) in patients with lymphoedma from lower extremities before and after administration of benzithine pencillin: A preliminary study. Lymphology. 1996;29::126-31.

9. Shenoy RK, Kumarswami V, Suma TK, Rajan K, Radhakuttyamma G. A double blind placebo controlled study of the efficacy of oral pencillin diethylcarbamazine or local treatment of thaffected limb in preventing acute adenolymphangitis in lymphodema caused by brugian filariasis. Ann Trop Med Parasitol. 1999;93:367-77.

10. ddiss DGD G. Treatment of lymphatic filariasis. In: Lymphatic Filariasis (Editor, TB Nutman). London: Imperial College Press; 2000. pp. 151-99.

11. Gass KMSH, Mwingira UJ, Nshala A, Chikawe M, Pelletreau S, et al. The rationale and costeffectiveness of a confirmatory mapping tool for lymphatic filariasis: Examples from Ethiopia and Tanzania. PLoS Negl Trop Dis. 2017;11(10).

12. Health. FDRoEMo. Second Edition of National Neglected Tropical Diseases Master Plan 2015/162019/20 (2008-2012 EFY). Addis Ababa, Ethiopia. 2016.

13. AMU. Training on lymphoedema morbidity management and disability prevention. 2020.

14. Kebede BMS, Mengistu B, Kebede B, Mengiste A, H/Kiros F, et al. Integrated morbidity mapping of lymphatic filariasis and podoconiosis cases in 20 co endemic districts of Ethiopia. PLoS Negl Trop Dis 2018;12(7).

15. Organization WH. Learner's Guide: Training Module on Community Home-Based Prevention of Disability due to Lymphatic Filariasis. Document No. WHO/CDS/CPE/CEE/2003-35, Part 1. Geneva: World Health Organization; 2003.

16. Deribe KWS, Shafi O, Tukahebwa EM, Umulisa I, Molyneux DH, Davey G. The feasibility of eliminating podoconiosis. Bulletin of the World Health Organization. 93. 2015:712-8.

17. Bereket Alemayehu MA. Factors Associated With Lymphoedema Management Success Among Podoconiosis Patients In Wolaita Zone, Southern Ethiopia. Science Journal Of Public Health. 2017;5:392-400.

18. FMOH. Elimination Of Neglected Tropical Diseases (NTDS) in Ethiopia for woreda level coordination toolkit for the WASH and NTD sectors. 


\section{Tables}

Table 1: Socio-demographic characteristics of lymphedema patients in Boreda district, Gamo zone, SNNPR, Ethiopia, 2021. ( $\mathrm{N}=280)$ : (*others= Merchant and Day laborer) 


\begin{tabular}{|c|c|c|c|}
\hline Variables & Category & Frequency & Percentage (\%) \\
\hline \multirow[t]{5}{*}{ Age (in years) } & 20 and below & 13 & 4.6 \\
\hline & $21-30$ & 32 & 11.4 \\
\hline & $31-40$ & 60 & 21.5 \\
\hline & $41-50$ & 54 & 19.3 \\
\hline & 51 and above & 121 & 43.2 \\
\hline \multirow[t]{2}{*}{ Gender } & Male & 111 & 39.6 \\
\hline & Female & 169 & 60.4 \\
\hline \multirow[t]{3}{*}{ Religion } & Adventist & 13 & 4.6 \\
\hline & Orthodox & 78 & 27.9 \\
\hline & Protestant & 189 & 67.5 \\
\hline \multirow[t]{3}{*}{ Ethnicity } & Amhara & 15 & 5.4 \\
\hline & Gamo & 263 & 93.9 \\
\hline & Wolayta & 2 & 0.7 \\
\hline \multirow[t]{3}{*}{ Educational background } & No formal education & 180 & 64.3 \\
\hline & Primary education (grade 1-8) & 88 & 31.4 \\
\hline & Secondary and above & 12 & 4.3 \\
\hline \multirow[t]{4}{*}{ Marital status } & Divorced & 2 & 0.7 \\
\hline & Married & 218 & 77.9 \\
\hline & Single & 30 & 10.7 \\
\hline & Widowed & 30 & 10.7 \\
\hline \multirow[t]{4}{*}{ Occupation } & Farmer & 105 & 37.5 \\
\hline & Housewife & 139 & 49.6 \\
\hline & Student & 23 & 8.2 \\
\hline & Others* & 13 & 4.7 \\
\hline \multirow[t]{4}{*}{ Wealth index } & Lowest & 61 & 21.8 \\
\hline & Second & 54 & 19.3 \\
\hline & Middle & 97 & 34.6 \\
\hline & Fourth & 17 & 6.1 \\
\hline
\end{tabular}




\begin{tabular}{|llll|}
\hline Variables & Category & Frequency & Percentage (\%) \\
\hline Highest & 51 & 18.2 \\
\hline
\end{tabular}

Table 2: Home-environmental characteristics of the study participants, $\mathrm{N}=280$

\begin{tabular}{|c|c|c|c|}
\hline Variables & Category & Frequency & $\begin{array}{l}\text { Percentage } \\
\text { (\%) }\end{array}$ \\
\hline \multirow[t]{2}{*}{$\begin{array}{l}\text { Distance from home to safe drinking water (one round } \\
\text { walking distance in minute) }\end{array}$} & $\begin{array}{l}30 \text { minute and } \\
\text { below }\end{array}$ & 191 & 68.2 \\
\hline & $\begin{array}{l}\text { Above } 30 \\
\text { minute }\end{array}$ & 89 & 31.8 \\
\hline \multirow[t]{2}{*}{ Number of litres of drinking water fetched per day } & 50 or below & 212 & 75.7 \\
\hline & Above 50 & 68 & 24.3 \\
\hline \multirow[t]{3}{*}{ Latrine conditions } & No latrine & 3 & 1.1 \\
\hline & $\begin{array}{l}\text { Functional pit } \\
\text { latrine }\end{array}$ & 264 & 94.3 \\
\hline & $\begin{array}{l}\text { Non- } \\
\text { functional } \\
\text { latrine }\end{array}$ & 13 & 4.6 \\
\hline \multirow[t]{2}{*}{ Weather conditions } & Mid-land & 44 & 15.7 \\
\hline & lowland & 236 & 84.3 \\
\hline \multirow[t]{3}{*}{ Type of soil } & Red clay soil & 228 & 81.4 \\
\hline & Sandy soil & 13 & 4.6 \\
\hline & Black soil & 39 & 14 \\
\hline
\end{tabular}

Table 3: Personal hygiene behaviour of lymphoedema patients in the study area, $\mathrm{N}=280$ 


\begin{tabular}{|c|c|c|c|}
\hline Variables & Category & Frequency & $\begin{array}{l}\text { Percentage } \\
\text { (\%) }\end{array}$ \\
\hline \multirow{4}{*}{$\begin{array}{l}\text { Situations in which patients walk } \\
\text { barefooted }\end{array}$} & Never barefooted & 167 & 59.6 \\
\hline & No habit of shoe wearing & 7 & 2.5 \\
\hline & Barefooted when farming & 33 & 11.8 \\
\hline & Barefooted when at home & 73 & 26.1 \\
\hline \multirow[t]{2}{*}{ Age at which shoes worn } & 20 year or below & 196 & 70 \\
\hline & Above 20 year & 84 & 30 \\
\hline \multirow[t]{3}{*}{ Number of pairs of shoes owned } & Only one pair & 55 & 19.6 \\
\hline & Two pair & 186 & 66.4 \\
\hline & Three or more pair & 39 & 14 \\
\hline \multirow{2}{*}{$\begin{array}{l}\text { Number of pairs of shoes needed per } \\
\text { year }\end{array}$} & 4 or less pairs & 177 & 63.2 \\
\hline & Above 4 pairs & 103 & 36.8 \\
\hline \multirow[t]{5}{*}{$\begin{array}{l}\text { Conditions where patients take care their } \\
\text { legs }\end{array}$} & $\begin{array}{l}\text { Wash legs with water and } \\
\text { soap }\end{array}$ & 137 & 49 \\
\hline & Wash legs with water only & 56 & 20 \\
\hline & No habit of washing legs & 0 & 0 \\
\hline & Washed legs last night & 246 & 87.9 \\
\hline & $\begin{array}{l}\text { Washed lags daily last } \\
\text { week }\end{array}$ & 215 & 76.8 \\
\hline
\end{tabular}

Table 4: Clinical history and personal hygiene characteristics of patients, $N=280$ 


\begin{tabular}{|c|c|c|c|}
\hline Variables & Category & Frequency & percentage \\
\hline \multirow[t]{2}{*}{ Wounds present on the affected legs } & Yes & 13 & 4.6 \\
\hline & No & 267 & 95.4 \\
\hline \multirow[t]{2}{*}{ If wounds present, do you clean the wound $(N=13)$} & Yes & 9 & 69.2 \\
\hline & No & 4 & 30.8 \\
\hline \multirow[t]{2}{*}{ Experienced acute attack of the affected leg } & Yes & 243 & 86.8 \\
\hline & No & 37 & 13.2 \\
\hline \multirow{3}{*}{$\begin{array}{l}\text { If experienced ALA, knew cause of acute attack }(N= \\
243)\end{array}$} & Don't know & 43 & 17.7 \\
\hline & $\begin{array}{l}\text { When } \\
\text { walking long } \\
\text { distance for } \\
\text { hours }\end{array}$ & 48 & 19.7 \\
\hline & $\begin{array}{l}\text { When } \\
\text { weather } \\
\text { condition } \\
\text { changes }\end{array}$ & 152 & 62.6 \\
\hline \multirow[t]{3}{*}{ Frequency of ALA occurrence, $(\mathrm{N}=243)$} & Monthly & 68 & 28 \\
\hline & $\begin{array}{l}\text { More than } \\
\text { once a month }\end{array}$ & 41 & 16.9 \\
\hline & Every year & 134 & 55.1 \\
\hline \multirow[t]{2}{*}{ Legs affected } & Both legs & 243 & 86.8 \\
\hline & Only one leg & 37 & 13.2 \\
\hline \multirow[t]{3}{*}{ Progression of swelling } & $\begin{array}{l}\text { Don't } \\
\text { remember }\end{array}$ & 39 & 13.9 \\
\hline & $\begin{array}{l}\text { From down } \\
\text { to up knee }\end{array}$ & 226 & 80.7 \\
\hline & $\begin{array}{l}\text { From hip to } \\
\text { down }\end{array}$ & 15 & 5.4 \\
\hline \multirow[t]{3}{*}{ Duration of swelling } & $\begin{array}{l}20 \text { years or } \\
\text { less }\end{array}$ & 170 & 60.7 \\
\hline & $21-40$ years & 99 & 35.4 \\
\hline & $\begin{array}{l}41 \text { and above } \\
\text { years }\end{array}$ & 11 & 3.9 \\
\hline \multirow[t]{2}{*}{ Family history of leg swelling } & Yes & 59 & 21.1 \\
\hline & No & 221 & 78.9 \\
\hline
\end{tabular}




\begin{tabular}{|c|c|c|c|}
\hline Variables & Category & Frequency & percentage \\
\hline \multirow[t]{4}{*}{ Number of family member affected $(\mathrm{N}=59)$} & One & 41 & 69.5 \\
\hline & Two & 12 & 20.3 \\
\hline & Three & 2 & 3.4 \\
\hline & Four & 4 & 6.8 \\
\hline \multirow{6}{*}{$\begin{array}{l}\text { Relationship with affected family member (one patient } \\
\text { might have more than one family member affected, } \\
\text { therefore total sum of percent became more than 100\%) }\end{array}$} & Father & 15 & 25.4 \\
\hline & Mother & 19 & 32.2 \\
\hline & Child & 25 & 42.4 \\
\hline & Sister & 8 & 13.6 \\
\hline & Brother & 7 & 11.9 \\
\hline & Grand family & 8 & 13.6 \\
\hline \multirow[t]{2}{*}{ Patient worn shoes at the time of interview } & Yes & 233 & 83.2 \\
\hline & No & 47 & 16.8 \\
\hline \multirow{4}{*}{$\begin{array}{l}\text { Type of shoes patient worn at the time of interview }(N= \\
233)\end{array}$} & Canvas & 161 & 69.1 \\
\hline & $\begin{array}{l}\text { Fully covered } \\
\text { leather }\end{array}$ & 2 & 0.9 \\
\hline & Hard plastic & 1 & 0.4 \\
\hline & Open shoes & 69 & 29.6 \\
\hline \multirow[t]{2}{*}{ Cleanliness of legs } & $\begin{array}{l}\text { Clean and } \\
\text { intact }\end{array}$ & 138 & 49.3 \\
\hline & Not clean & 142 & 50.7 \\
\hline \multirow[t]{2}{*}{ Odor of the leg } & No odor & 213 & 76.1 \\
\hline & Has bad odor & 67 & 23.9 \\
\hline
\end{tabular}

Table 5: Accessibility of the respondents for health care services in Boreda district, Southern Ethiopia, 2021. 


\begin{tabular}{|c|c|c|c|}
\hline Variables & Category & Frequency & percentage \\
\hline \multirow{2}{*}{$\begin{array}{l}\text { Patients attend lymphoedema } \\
\text { management service }\end{array}$} & Yes & 164 & 58.6 \\
\hline & No & 116 & 41.4 \\
\hline \multirow{3}{*}{$\begin{array}{l}\text { Reasons for not attending LMMDP service } \\
(\mathrm{N}=116)\end{array}$} & Didn't want & 62 & 53.5 \\
\hline & $\begin{array}{l}\text { Health facility far from } \\
\text { home }\end{array}$ & 7 & 6 \\
\hline & $\begin{array}{l}\text { No treatment centre in the } \\
\text { area }\end{array}$ & 47 & 40.5 \\
\hline \multirow[t]{2}{*}{ Type of health facility attended $(\mathrm{N}=164)$} & Health centre & 154 & 93.9 \\
\hline & Hospital & 10 & 6.1 \\
\hline \multirow{2}{*}{$\begin{array}{l}\text { Trained on self-care management of foots } \\
(\mathrm{N}=164)\end{array}$} & Yes & 94 & 57.3 \\
\hline & No & 70 & 42.7 \\
\hline \multirow{2}{*}{$\begin{array}{l}\text { Graduated from health extension } \\
\text { packages? }\end{array}$} & Yes & 17 & 6.1 \\
\hline & No & 263 & 93.9 \\
\hline
\end{tabular}

Table 6: Practice of study participants towards lymphedema morbidity management and disability prevention, Boreda district, Southern Ethiopia, 2021 


\begin{tabular}{|c|c|c|c|}
\hline Variables & Category & Frequency & Percentage \\
\hline \multirow[t]{2}{*}{ Washing legs with water and soap daily } & Yes & 137 & 48.9 \\
\hline & No & 143 & 51.1 \\
\hline \multirow[t]{2}{*}{ Habit of drying legs after washing } & Yes & 23 & 8.2 \\
\hline & No & 257 & 91.8 \\
\hline \multirow[t]{2}{*}{ Habit of cleaning legs apart from washing } & Yes & 28 & 10 \\
\hline & No & 252 & 90 \\
\hline \multirow[t]{2}{*}{ Habit of massaging legs } & Yes & 201 & 71.8 \\
\hline & No & 79 & 28.2 \\
\hline \multirow[t]{2}{*}{ Habit of elevating legs } & Yes & 114 & 40.7 \\
\hline & No & 166 & 59.3 \\
\hline \multirow[t]{2}{*}{ Exercise the affected legs } & Yes & 74 & 26.4 \\
\hline & No & 206 & 73.6 \\
\hline \multirow[t]{2}{*}{ Patients worn shoes during interview } & Yes & 233 & 83.2 \\
\hline & No & 47 & 16.8 \\
\hline \multirow[t]{2}{*}{ Cleanliness of legs observed } & Yes & 138 & 49.3 \\
\hline & No & 142 & 50.7 \\
\hline \multirow[t]{2}{*}{ Patients never walk barefooted } & Yes & 192 & 68.6 \\
\hline & No & 88 & 31.4 \\
\hline \multirow[t]{2}{*}{ Overall practice on foot care } & Good practice & 127 & 45.4 \\
\hline & Poor practice & 153 & 54.6 \\
\hline
\end{tabular}

Table 7: Factors associated with foot care practice among lymphoedema patients in Boreda district, Gamo zone, Southern Ethiopia, 2021. (*significantly associated with foot care practice; **strongly associated with foot care practice) 


\begin{tabular}{|c|c|c|c|c|c|c|}
\hline \multirow[t]{2}{*}{ Variables } & \multirow[t]{2}{*}{ Category } & \multicolumn{2}{|c|}{$\begin{array}{l}\text { Status of foot } \\
\text { care practice }\end{array}$} & \multirow[t]{2}{*}{$\begin{array}{l}\text { COR with } \\
95 \% \mathrm{Cl}\end{array}$} & \multirow[t]{2}{*}{$\begin{array}{l}\text { AOR with } \\
95 \% \mathrm{Cl}\end{array}$} & \multirow[t]{2}{*}{$\begin{array}{l}\mathrm{P} \text { - } \\
\text { values }\end{array}$} \\
\hline & & Good & Poor & & & \\
\hline \multirow[t]{5}{*}{ Wealth index } & $\begin{array}{l}\text { First } \\
\text { percentile }\end{array}$ & 31 & 30 & $\begin{array}{l}3.029(1.35 \\
6.758)\end{array}$ & $\begin{array}{l}2.621 \\
(0.838 \\
8.193)\end{array}$ & 0.098 \\
\hline & $\begin{array}{l}\text { Second } \\
\text { percentile }\end{array}$ & 32 & 22 & $\begin{array}{l}4.25(1.85 \\
9.76)\end{array}$ & $\begin{array}{l}1.213 \\
(0.376 \\
3.908)\end{array}$ & 0.747 \\
\hline & $\begin{array}{l}\text { Middle } \\
\text { percentile }\end{array}$ & 45 & 52 & $\begin{array}{l}2.53(1.2 \\
5.3)\end{array}$ & $\begin{array}{l}1.468 \\
(0.533, \\
4.042)\end{array}$ & 0.457 \\
\hline & $\begin{array}{l}\text { Fourth } \\
\text { percentile }\end{array}$ & 6 & 11 & $\begin{array}{l}1.59(0.49 \\
5.175)\end{array}$ & $\begin{array}{l}0.261(0.047 \\
1.431)\end{array}$ & 0.122 \\
\hline & $\begin{array}{l}\text { Fifth } \\
\text { percentile }\end{array}$ & 13 & 38 & - & & \\
\hline \multirow[t]{2}{*}{$\begin{array}{l}\text { Number of litres of } \\
\text { water fetched per day }\end{array}$} & 50 or below & 79 & 133 & $\begin{array}{l}0.247(0.137 \\
0.447)\end{array}$ & $\begin{array}{l}0.383(0.155 \\
0.945)\end{array}$ & $0.037^{\star}$ \\
\hline & Above 50 litre & 48 & 20 & Reference & - & \\
\hline \multirow[t]{2}{*}{$\begin{array}{l}\text { Age at which shoes } \\
\text { first worn }\end{array}$} & $\begin{array}{l}20 \text { or years } \\
\text { old }\end{array}$ & 108 & 88 & Reference & & \\
\hline & $\begin{array}{l}\text { Above } 20 \\
\text { years old }\end{array}$ & 19 & 65 & $\begin{array}{l}0.238(0.133 \\
0.427)\end{array}$ & $\begin{array}{l}0.261(0.107 \\
0.63)\end{array}$ & $0.003^{\star}$ \\
\hline \multirow[t]{3}{*}{$\begin{array}{l}\text { Number of shoes } \\
\text { owned }\end{array}$} & $\begin{array}{l}\text { Only one pair } \\
\text { of shoes }\end{array}$ & 15 & 40 & $\begin{array}{l}0.167(0.068 \\
0.41)\end{array}$ & $\begin{array}{l}0.04(0.009 \\
0.182)\end{array}$ & $0.001^{\star \star}$ \\
\hline & $\begin{array}{l}\text { Two pairs of } \\
\text { shoes }\end{array}$ & 85 & 101 & $\begin{array}{l}0.374(0.179 \\
0.783)\end{array}$ & $\begin{array}{l}0.27(0.087 \\
0.85)\end{array}$ & $0.026^{\star}$ \\
\hline & $\begin{array}{l}\text { Three or more } \\
\text { pairs }\end{array}$ & 27 & 12 & Reference & - & \\
\hline \multirow{2}{*}{$\begin{array}{l}\text { Attended LMMDP } \\
\text { treatment }\end{array}$} & No & 30 & 86 & Reference & & \\
\hline & Yes & 97 & 67 & $\begin{array}{l}4.15(2.469 \\
6.976)\end{array}$ & $\begin{array}{l}3.339(1.53 \\
7.285)\end{array}$ & $0.002^{\star}$ \\
\hline \multirow[t]{3}{*}{$\begin{array}{l}\text { Frequency of acute } \\
\text { attack }\end{array}$} & Every month & 50 & 18 & $\begin{array}{l}6.77(3.514 \\
13.028)\end{array}$ & $\begin{array}{l}\text { 8.15(3.157, } \\
21.058)\end{array}$ & $0.001^{\star \star}$ \\
\hline & $\begin{array}{l}\text { Twice or more } \\
\text { in a month }\end{array}$ & 29 & 12 & $\begin{array}{l}5.89(2.73 \\
12.7)\end{array}$ & $\begin{array}{l}9.35(3.118 \\
28.059)\end{array}$ & $0.001^{\star \star}$ \\
\hline & Once per year & 39 & 95 & Reference & & \\
\hline
\end{tabular}


Figures

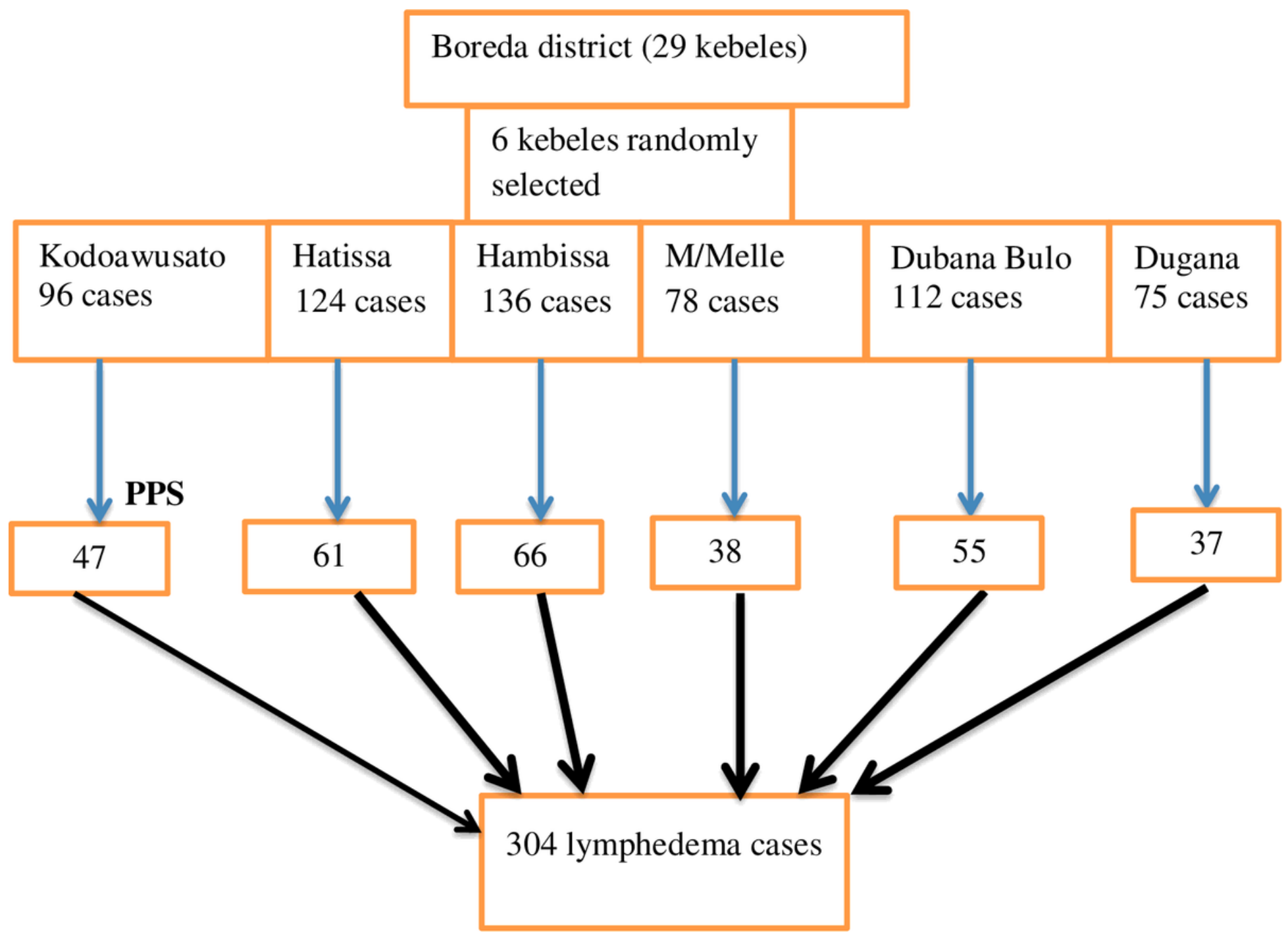

Figure 1

schematic presentation of sampling procedure to assess foot care practice and associated factors among people living with lymphoedema in Boreda district, Gamo zone, southern Ethiopia, 2020 


\section{Foot care practice}

\section{Good practice $\quad$ Poor practice}

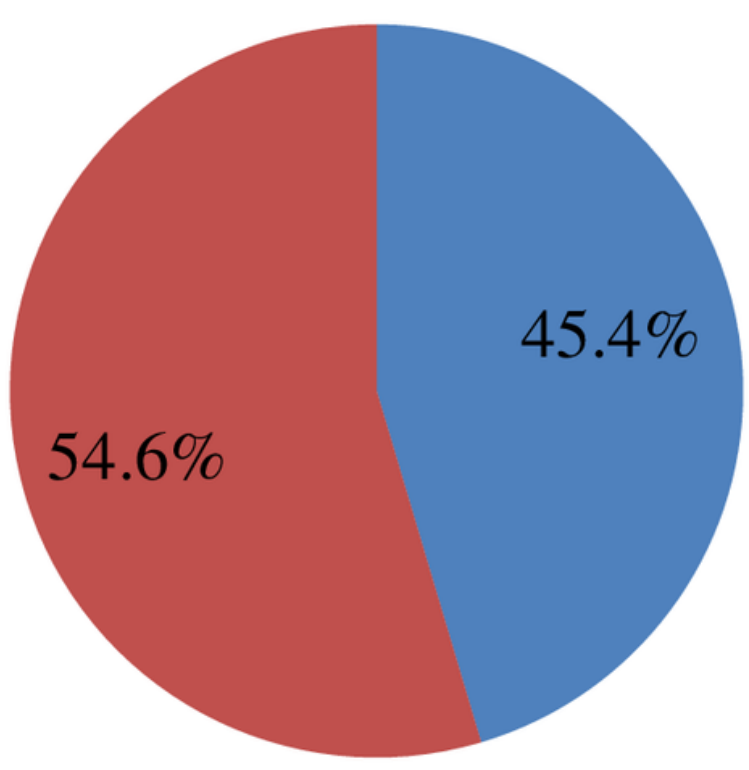

Figure 2

Overall status of foot care practice of the study participants 